\title{
Evaluation of Microbial Samplers for Bacterial Microorganisms
}

\author{
Chih-Shan Li*, Mei-Ling Hao, Wen-Hai Lin, Ching-Wen Chang, \\ and Chiu-Sen Wang \\ GRADUATE INSTITUTE OF ENVIRONMENTAL HEALTH, COLLEGE OF PUBLIC HEALTH, \\ NATIONAL TAIWAN UNIVERSITY, TAIPEI, TAIWAN, R.O.C. (C.-S.L., M.-L.H., W.-H. L., AND \\ C.-W.S.), INSTITUTE OF OCCUPATIONAL SAFETY AND HEALTH, COUNCIL OF LABOR, \\ TAIPEI, TAIWAN, R.O.C. (C.-S.W.)
}

\begin{abstract}
The influences of physical factors, sampling time, and flow rates on total recovery rate of airborne bacteria were evaluated in a chamber by three sampling methods: AGI-30 all-glass impingers, Nuclepore filtration and elution method, and gelatin filters. The influence of the biological factor, microorganism hardiness, was assessed by using sensitive Escherichia coli (E. coli) and hardy Bacillus subtilis (B. subtilis) spores. It was found that colony or relative survival of sensitive $E$. coli was much lower than those of hardy $B$. subtilis spores by the evaluated three sampling methods. Sampling flow rate did not have a significant influence on the bacterial recovery by the three sampling methods. However, the relative survival of sensitive $E$. coli collected on Nuclepore and gelatin filters became lower as the sampling time increased because of dehydration effects. For hardy $B$. subtilis spores, it was demonstrated that recovery by gelatin filter was comparable to that by impinger. In conclusion, it was found that impingers could perform much better than filtration methods for sampling airborne bacterial bioaerosols.
\end{abstract}

\section{INTRODUCTION}

Currently, bioaerosol characterization has become an important issue because of their related health effects. Therefore, it is necessary to assess composition and concentration of airborne microorganisms in contaminated indoor/outdoor or occupational environments (Henningson and Ahlberg 1994). In general, field evaluations in the natural environment are likely to provide very limited information with uncontrolled or unknown natural aerosol con-

${ }^{*}$ Corresponding author. centrations, particle sizes, and flora (Henningson and Ahlberg 1994; Nevalainen et al. 1993). Thus, it is necessary to use a test aerosol in chamber to assess bioaerosol sampler performance (Griffiths and DeCosemo 1994).

The overall sampling efficiency of bioaerosol samplers with different designs may differ significantly from one another because of the different physical collection efficiency and the stress imparted to the microorganisms. The selection of sampler, microorganism hardiness, sampling time, and sampling flow rate are considered to be the most important factors to affect microbial collection and survival in bioaerosol sam- 
plers (Macher and Willeke 1992; Nevalainen et al. 1993).

In this study, the performance of the commonly used bioaerosol sampling methods AGI30 impingers, Nuclepore filtration and elution method, and gelatin filters in highly contaminated environments was evaluated. In addition, the influences of sampling time and flow rates, microorganism hardiness, and aerosol concentrations on the recovery of the viable bacterial aerosols were also investigated.

\section{MATERIALS AND METHODS}

\section{Test Microorganisms}

Cultures used in this evaluation included E. coli and B. subtilis from Graduate Institute of Microbiology, College of Medicine, National Taiwan University. The recovery of gram-negative and nonspore-forming $E$. coli, representative of a sensitive bacterial strain, could be used to assess the effect of the microorganism hardiness on sampler performance in comparison with that of gram-positive, endospore-forming, and hardy B. subtilis.

An active E. coli culture was inoculated into approximately 10 TSA (trypticase soy agar, Difco) plates and incubated for $24 \mathrm{~h}$ at $37^{\circ} \mathrm{C}$ (Jensen et al. 1992). The colonies were later aseptically washed to a $15-\mathrm{ml}$ sterile conical centrifuge tube (SARSTEDT, Germany), capped, and centrifuged at 2,500 rpm for $5 \mathrm{~min}$. For $B$. subtilis, the cells were initially inoculated on 10 TSA plates for sporulation at $37^{\circ} \mathrm{C}$ for 7 days. Bacterial growth was harvested into sterile distilled water, agitated at $45 \mathrm{rpm}$ for more than $24 \mathrm{~h}$ at room temperature, and heated for $10 \mathrm{~min}$ in an $80^{\circ} \mathrm{C}$ water bath to kill vegetative cells. Microscopic examination of the suspension of B. subtilis demonstrated motile, single cells with an endospore intact and a minute amount of cell debris. The resulting spore suspension was centrifuged at 3,500 rpm for $5 \mathrm{~min}$. The supernatants of both strains were discarded and the pellets were resuspended in sterile dis- tilled water. This washing process was repeated two more times and the cells/spores were then resuspended in approximately $70 \mathrm{ml}$ of sterile distilled water for high-concentration generation. The resuspended solution was diluted 100 times for medium-concentration generation.

\section{Aerosol Generation and Test system}

The test system was a modification of the system previously developed by Thompson et al. (1994). The test chamber is $12.5 \mathrm{~cm}$ in diameter with a height of $27 \mathrm{~cm}$. A Collison three-jet nebulizer (BGI Inc., Waltham, MA) was used for nebulization of the microbial E. coli and B. subtilis suspension at $3 \mathrm{~L} / \mathrm{min}$ of dry, filtered, and compressed laboratory air, then passed through a Kr-85 particle charge neutralizer (model 3077 , TSI). The aerosolized suspension was then diluted with filtered and compressed air at 50 $\mathrm{L} / \mathrm{min}$.

The Aerosizer, an aerodynamic particle sizer (Model 8000, API Inc., Hadley, MA) was used to determine real-time number concentration $\left(\mathrm{C}_{0}, \# / \mathrm{m}^{3}\right)$ and size distribution of bacterial aerosol throughout the run in order to determine total recovery (TR, $\left.\mathrm{C}_{\text {test }} / \mathrm{C}_{0}\right)$ of $E$. coli and $B$. subtilis by the test samplers $\left(\mathrm{C}_{\text {test }}, \mathrm{CFU} / \mathrm{m}^{3}\right)$. The Aerosizer is capable of measuring particles larger than $0.5 \mu \mathrm{m}$ at an airflow rate of $6 \mathrm{~L} / \mathrm{min}$ (Qian et al. 1995). To determine the relative survival ( $\mathrm{RS}, \mathrm{C}_{\text {test }} / \mathrm{C}_{\text {ref }}$ ), the evaluated sampler was placed in the test chamber together with the reference sampler, the AGI-30 impinger at a flow rate of $12.5 \mathrm{~L} / \mathrm{min}\left(\mathrm{C}_{\text {ref }}, \mathrm{CFU} / \mathrm{m}^{3}\right)$, which was widely applied in field measurement. During the tests, the bacterial concentrations were maintained at $10^{6}$ (medium) and $10^{8}$ (high) particles $/ \mathrm{m}^{3}$, which represented the medium to highly contaminated environments, for at least $3 \mathrm{~h}$. The entire system was placed in a safety cabinet to eliminate the uncollected bioaerosols by the samplers. During the course of the experiments, the temperature was in the range of $20-24^{\circ} \mathrm{C}$ and relative humidity was maintained at $60 \%$. 


\section{Test Sampler}

The AGI-30 (Ace Glass Inc., Vineland, NJ) is an all-glass impinger with $30 \mathrm{~mm}$ jet-to-plate distance. It was developed from the Porton impinger for sampling microorganisms (May and Harper 1957) and proposed as a reference sampler (Brachman et al. 1964). Twenty ml of sterile deionized water with $1 \%$ peptone, $0.01 \%$ Tween 80, and $0.005 \%$ antifoam A (Sigma Chemical Co., St. Louis, MO) was put into each autoclaved AGI-30 impinger (Thorne et al. 1992). The antifoam was added to reduce foaming and to prevent excessive fluid loss (Lembke et al. 1981).

A Nuclepore filter (Costar, Cambridge, MA) is a track-etched polycarbonate filter consisting of a polycarbonate membrane with straightthrough pores of a uniform size $(0.01-14 \mu \mathrm{m}$ pore size). In this study, filters with $0.4 \mu \mathrm{m}$ pore size and $37 \mathrm{~mm}$ diameter supported by cellulose pads were loaded into open-face, threepiece plastic cassettes. Filters and support pads were autoclaved and plastic cassettes were sterilized with ethylene oxide before sampling.

The gelatin filter (Sartorius, Gottingen, Germany) has been specially designed for detection and analysis of airborne microbes. Each sterile gelatin filter $(3.0 \mu \mathrm{m}$ pore size, $80 \mathrm{~mm}$ diameter) was placed in a sterile filter holder by carefully letting the filter slide out of the pocket onto the filter support of the aluminum filter holder.

\section{Sampling time and flow rates}

To evaluate the influence of sampling time on the collection of viable airborne bacterial particulates, the selected sampling times included $1,2.5,5,15,30,45$, and $60 \mathrm{~min}$. For the AGI-30 impinger, the sampling flow rates consisted of $4.7,7.1,9.4,12.5$, and $14 \mathrm{~L} / \mathrm{min}$ and the corresponding velocities through the nozzle were $100,150,200,265$, and $300 \mathrm{~m} / \mathrm{s}$, respectively. Regarding Nuclepore filters, the four sampling flow rates were selected to be $1,1.5,2$, and 4 $\mathrm{L} / \mathrm{min}$ and the corresponding sampling velocities were $2,3,4$, and $8 \mathrm{~cm} / \mathrm{s}$, respectively. In ad- dition, the four air flow rates used for the gelatin filters were $10,15,20$, and $30 \mathrm{~L} / \mathrm{min}(4,6,8$, and $12 \mathrm{~cm} / \mathrm{s}$ ), which were widely used by industrial hygienists and matched with the sampling velocity selection for track-etched polycarbonate filtration.

\section{Sample processing}

After sampling, the bacterial particles on the filters were removed. The Nuclepore samples were eluted by injecting $1 \mathrm{ml}$ of filtered and sterile water with $0.1 \%$ peptone and $0.01 \%$ Tween 80 into the support pad and $5 \mathrm{ml}$ of the same medium onto the filter surface (Thorne et al. 1992). The cassettes were recapped and vortexed in rotator (Vortex-2 Genie, G-560, Scientific Industries Inc.) for $30 \mathrm{~s}$. The gelatin filter was moved carefully into a $90 \mathrm{~mm}$ petri dish and dissolved in $10 \mathrm{ml}$ of sterile deionized water in a $40^{\circ} \mathrm{C}$ water bath for 5-15 min. The suspensions from both filters were then vortexed and duplicate $0.2 \mathrm{ml}$ samples of serial 10 -fold dilution were plated onto TSA. The agar plates were incubated for $24 \mathrm{~h}$ at $37^{\circ} \mathrm{C}$.

Colony forming unit (CFU) counting was done on plates containing between 30 and 300 colonies (Thorne et al. 1992). Airborne bacterial concentrations were determined by multiplying the CFU by the dilution factor and by the elute volume and dividing by the volume of serial dilution material plated $(0.2 \mathrm{ml})$ and the volume of sampled air which was calculated from sampling time and flow rate.

\section{RESULTS AND DISCUSSION}

\section{Characteristics of aerosolized E. coli and $B$. subtilis spores}

The aerodynamic particle diameter of the target aerosol is one of the most important physical factors which determine the stage collection efficiencies of inertial and filtration devices. It was found that geometric mean aerodynamic diameter (GMAD) of E. coli and B. subtilis spores 
were in the range of $0.7-0.9 \mu \mathrm{m}$ with geometric standard deviation (GSD) of 1.2. In addition, the distributions of CFUs collected by the Andersen six-stage sampler for $E$. coli and $B$. subtilis spores indicated that more than $98 \%$ of the recovered colonies were $\leq 2.1 \mu \mathrm{m}$ (data not shown).

In addition to size characteristics, the viability of the generated bacteria is another important factor to affect sampling performance. In our current investigation, it was observed that the viability of prepared $B$. subtilis spores was lower than that of prepared E. coli in the suspension solution by evaluating the ratio of $\mathrm{C}_{\text {susp }}(\mathrm{CFU} / \mathrm{ml}$ in suspension) to $C_{\mathrm{o}}$ (as shown in Table 1 ). The viability of the prepared bacterial strains depends on preparation process, which might vary from one to another investigation. Therefore, TRs could not be a good indicator for sampler bioefficiency comparison among different bacterial strains. It will be better to consider the bacterial viability in the liquid suspension, which was used as the source of the generated bacterial bioaerosols. It is recommended that $\mathrm{C}_{\text {test }} / \mathrm{C}_{\text {susp }}$ (colony survival, CS) rather than TR could be used as an indicator to evaluate sampler performance among bacteria with different viability.

\section{Bioefficiency of test samplers}

AGI-30 impinger. Bioefficiency analysis at different sampling times and flow rates indicated that the average values of CS for sensitive $E$. coli were observed to be $0.053,0.039,0.041,0.047$, $0.041,0.045$, and 0.04 at the sampling times of 1 ,
$2.5,5,15,30,45$, and $60 \mathrm{~min}$, respectively. For hardy B. subtilis, the average values of CS (\%) were $0.144,0.134,0.124,0.117,0.095,0.101$, and 0.104 at the sampling times of $1,2.5,5,15$, 30,45 , and $60 \mathrm{~min}$, respectively (as shown in Figure 1). It was demonstrated that sampling flow rates and time and aerosol concentrations did not have a significant influence on the CS performance of the impinger. However, bacterial hardiness was observed to play an important role in impinger collection. From the previous report (Lin et al. 1997), it was found that both sampling time and flow rates can affect the collection efficiency, bubble pattern (Grinshpun et al. 1997), and the culturability of collected bacteria for the AGI-30 impinger. Concerning sampling time, it was indicated that collection efficiency of $1.06 \mu \mathrm{m}$ PSL did not change significantly throughout the 60 min sampling period (Lin et al. 1997). Regarding sampling flow rates, the calculated cutoff diameter decreases and collection efficiency increases as flow rate increases (Nevalainen et al. 1992, 1993). Another important issue with which we are concerned was the evaporation and reaerosolization effect. In the current evaluation, an antifoam agent was added to reduce the evaporation rate of the collection solution. In addition, a wetting agent, Tween 80 , was added into the collection solution for enchancing the bacterial suspension during impingement. However, the effect of evaporation and reaerosolization on collection efficiency of the impinger still needs further evaluation.

In the current investigation, it was observed that the sampling flow rate did not significantly

TABLE 1. Comparison of viability of prepared $E$. coli and B. subtilis in suspension solutions

\begin{tabular}{|c|c|c|c|c|}
\hline \multirow[b]{2}{*}{ Aerosol Concentration } & \multicolumn{2}{|c|}{ E. coli } & \multicolumn{2}{|c|}{ B. subtilis } \\
\hline & Medium & High & Medium & High \\
\hline $\begin{array}{l}\text { Suspension Concentration } \\
\left(\mathrm{C}_{\text {susp }}, 10^{6} \mathrm{CFU} / \mathrm{ml}\right)\end{array}$ & 8.09 & 1590 & 1.38 & 143 \\
\hline $\begin{array}{l}\text { Aerosol Concentration } \\
\left(\mathrm{C}_{0}, 106 \mathrm{\#} / \mathrm{m}^{3}\right)\end{array}$ & 2.02 & 149 & 2.24 & 112 \\
\hline $\begin{array}{l}\mathrm{C}_{\text {susp }} / \mathrm{C}_{0} \\
\left(\mathrm{CFU} / \mathrm{ml} / \# / \mathrm{m}^{3}\right)\end{array}$ & 4.00 & 10.7 & 0.62 & 1.28 \\
\hline
\end{tabular}



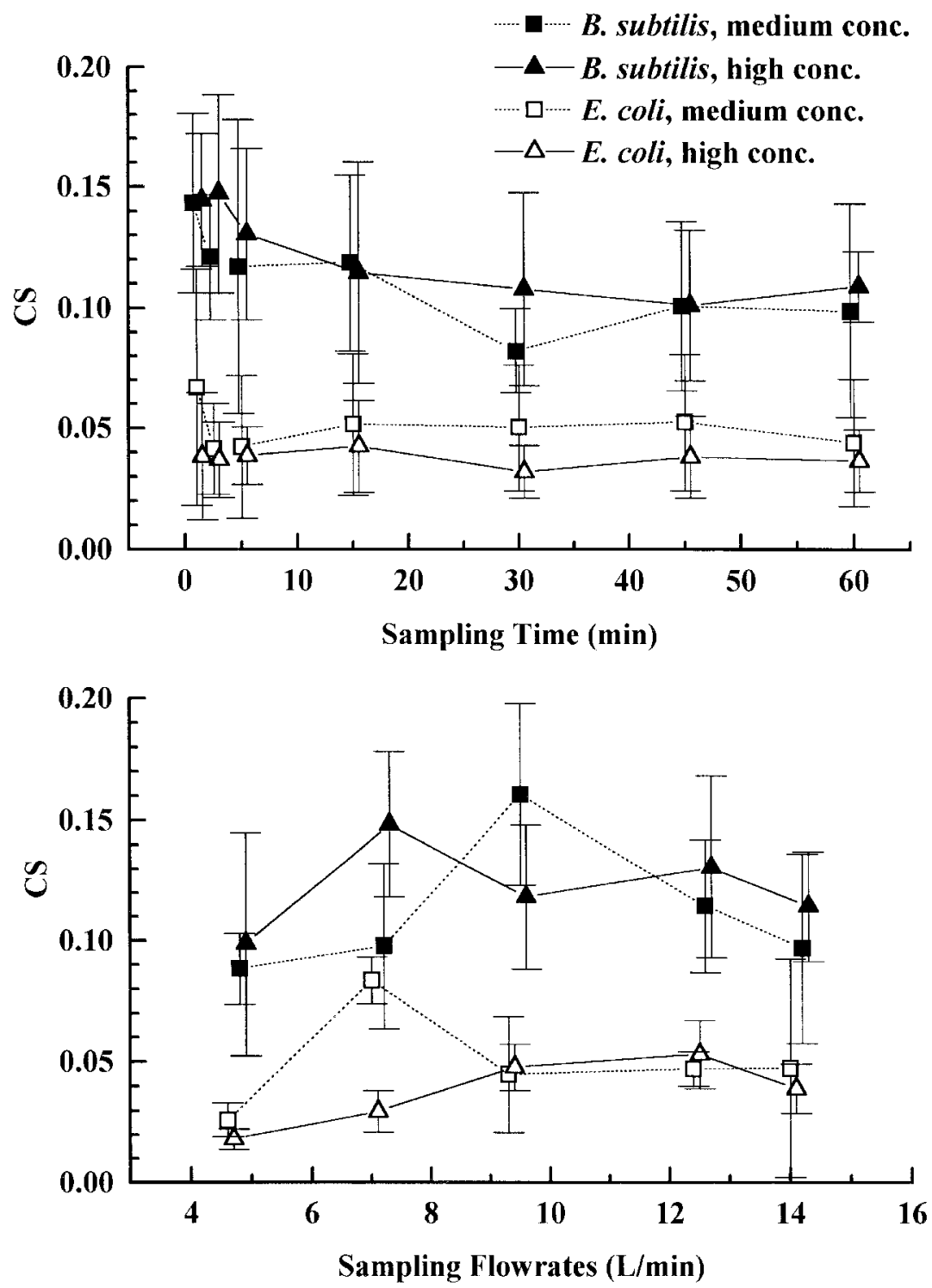

FIGURE 1. The average colony survival (CS: $\mathrm{CFU} / \mathrm{m}^{3} / \mathrm{CFU} / \mathrm{ml}, \mathrm{CFU} / \mathrm{m}^{3}$ concentration divided by $\mathrm{CFU} / \mathrm{ml}$ in suspension) of AGI-30 for $E$. coli and $B$. subtilis at different sampling times and flow rates. In the upper figure, each error bar represents one standard deviation on the mean of five different sampling flow rates. In the lower figure, each error bar represents one standard deviation on the mean of seven different sampling times.

influence the biological recovery of the collected bacteria. This should be related to a higher sampling flow rate resulting in higher biolog- ical stress, which affects the bacterial survival. For AGI-30 impingers, the biological stress during sampling consists of the impinging action 
through the nozzle of the inlet tube, impaction onto the bottom of the collection bottle, and contact effect with collection solution (Terzieva et al. 1996). The biological stress during impingement was found to be so destructive that the recoveries of sensitive E. coli were much lower than those of hardy $B$. subtilis.

Nuclepore filter. The average values of RS (\%) for sensitive $E$. coli were observed to be $55 \%$, $44 \%, 43 \%, 18 \%, 10 \%, 9 \%$, and $5 \%$ at the sampling times of $1,2.5,5,15,30,45$, and $60 \mathrm{~min}$, respectively. For hardy $B$. subtilis, the average values of $\mathrm{RS}(\%)$ were $64 \%, 51 \%, 51 \%, 47 \%$, $48 \%, 47 \%$, and $42 \%$ at the sampling time of 1 , $2.5,5,15,30,45$, and $60 \mathrm{~min}$, respectively (as shown in Figure 2). To be compared with the performance of the reference AGI-30 impinger, RSs of Nuclepore filter were found to be lower than $100 \%$. In addition, it was clearly demonstrated that flow rates did not significantly influence the performance of Nuclepore filters for collecting bacterial bioaerosols. Furthermore, the recoveries of hardy $B$. subtilis spores were demonstrated to be higher at high rather than medium concentrations. In addition, sampling time was indicated to play a role in RS (from $55 \%$ to $5 \%$ ) determination of sensitive $E$. coli recovery rather than hardy $B$. subtilis $(50 \%)$.

For the filter, the particle diameter of bacterial aerosols was much larger than the $0.4 \mathrm{~mm}$ pore size and the bacterial penetration through filter should be negligible. Therefore, it can be indicated that RS values are primarily related to the biological stress during filtration. The biological stress during filtration includes impaction and dehydration effects caused by the large volume of air over the collected bioaerosols (Jensen et al. 1992; Crook 1995). In the current evaluation, sampling time prolongation was found to reduce RS for sensitive $E$. coli, but not for $B$. subtilis. It was demonstrated that dehydration during sampling did significantly affect viability of sensitive bacteria which are not as resistant to desiccation as hardy ones.
Gelatin filter. The average RS (\%) values of gelatin filters for $E$. coli were observed to be $4 \%, 7 \%, 4 \%, 3 \%, 1 \%, 0.2 \%$, and $0.2 \%$ at the sampling times of $1,2.5,5,15,30,45$, and 60 min, respectively. Moreover, the average RS (\%) values of $B$. subtilis were observed to be $128 \%, 93 \%, 84 \%, 78 \%, 108 \%, 88 \%$, and $72 \%$ at the sampling times of $1,2.5,5,15,30,45$, and 60 min, respectively (as shown in Figure 3). It was demonstrated that the recovery of $B$. subtilis by gelatin filter was as good as that by impinger. However, the recovery of $E$. coli by gelatin filter was found to be close to zero, which agreed with those reported by Macher and First (1984). Similarly to the performance of the Nuclepore filter, the gelatin filter performance was not significantly influenced by sampling flow rates.

The collection efficiency has been observed to be $99.9 \%$ for particles of $0.5-3 \mu \mathrm{m}$ despite the fact that the filter pore size is as large as 3 $\mu \mathrm{m}$ (Rotter and Koller 1973) and is comparable to that of cellulose acetate membrane filters (Macher and First 1984). Therefore, the influence of physical factors (such as sampling flow rate and time) on collection efficiency of gelatin filters should be negligible.

Generally speaking, gelatin filters are considered to be unsatisfactory for collecting airborne bacteria because during extended sampling the gelatin dried out, placing additional dehydration stresses on the collected microorganisms (Crook 1995). In the current evaluation, sampling time was still found to affect RS of gelatin filter, more for sensitive $E$. coli than for hardy $B$. subtilis spores. Our data clearly demonstrated that the hardy spores could be retrieved more readily than the sensitive strains on gelatin and Nucelpore filters.

The physical collection efficiency of filtration was higher than that of impingers for collecting bacterial bioaerosols. Therefore, the observed lower RS values of filtration compared to impingement should be associated with the higher biological stress by filtration, which was related to dehydration stress. 


\section{-......... B. subtilis, medium conc. \\ - $\Delta$ - B. subtilis, high conc. \\ …. $\square \cdots \cdot$ E. . coli, medium conc. \\ $-\Delta-E$. coli, high conc.}
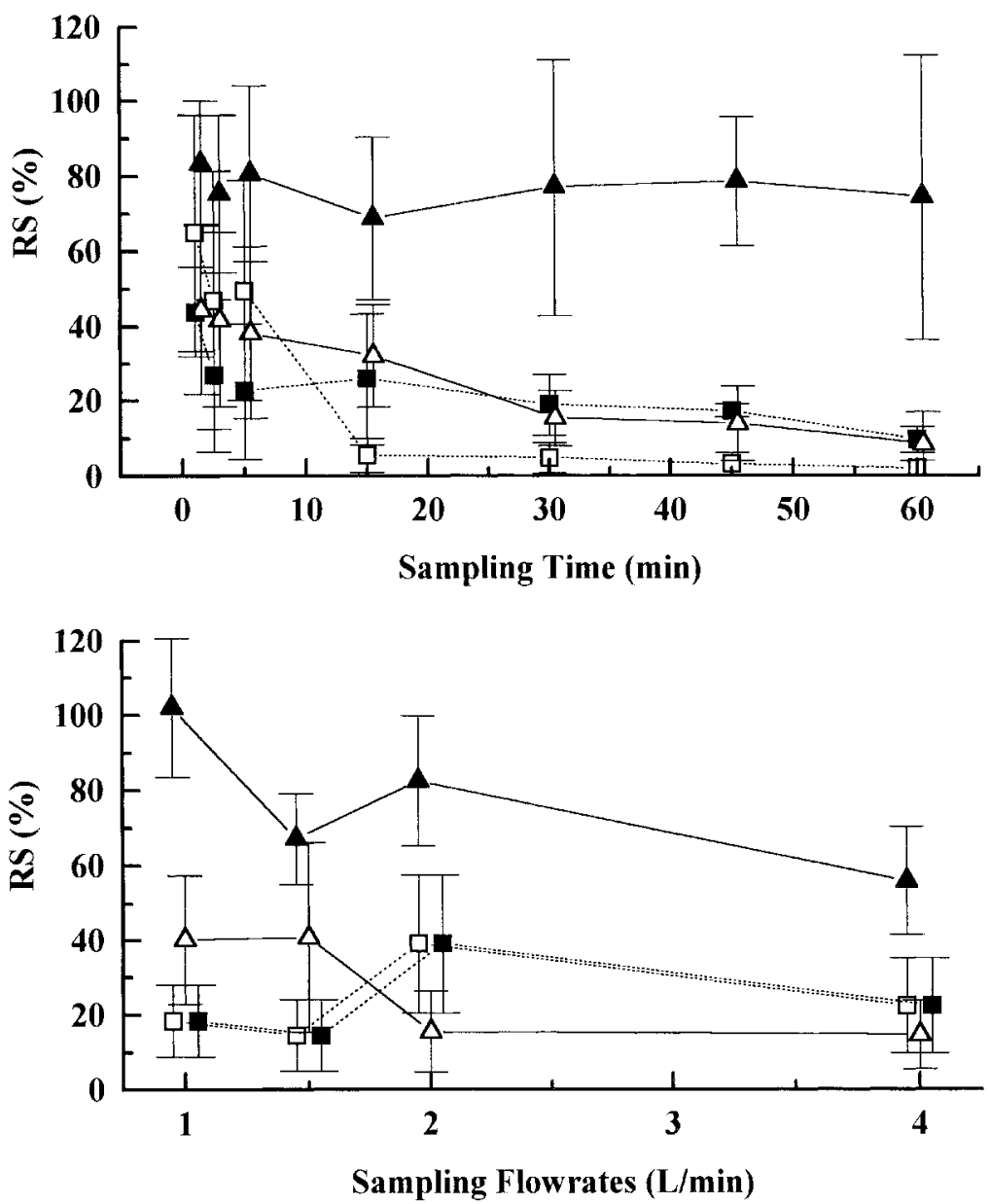

FIGURE 2. The average relative survival (RS in $\%: \mathrm{CFU} / \mathrm{m}^{3}$ concentration divided by $\mathrm{CFU} / \mathrm{m}^{3}$ concentration measured simultaneously by an AGI-30 at a flow rate of $12.5 \mathrm{~L} / \mathrm{min}$ ) of Nucelpore filters for $E$. coli and $B$. subtilis at different sampling times and flow rates. In the upper figure, each error bar represents one standard deviation on the mean of four different sampling flow rates. In the lower figure, each error bar represents one standard deviation on the mean of seven different sampling times.

\section{CONCLUSIONS}

The observed lower level of total bacterial recovery on filter as compared to impinger is primarily due to the higher biological stress during the sampling process of filtration. Furthermore, the sampling flow rate did not have a significant influence on the bacterial recovery. Sampling time related to dehydration effect did play a role on the bacterial recoveries, especially for the sensitive strain. In summary, impingers are 

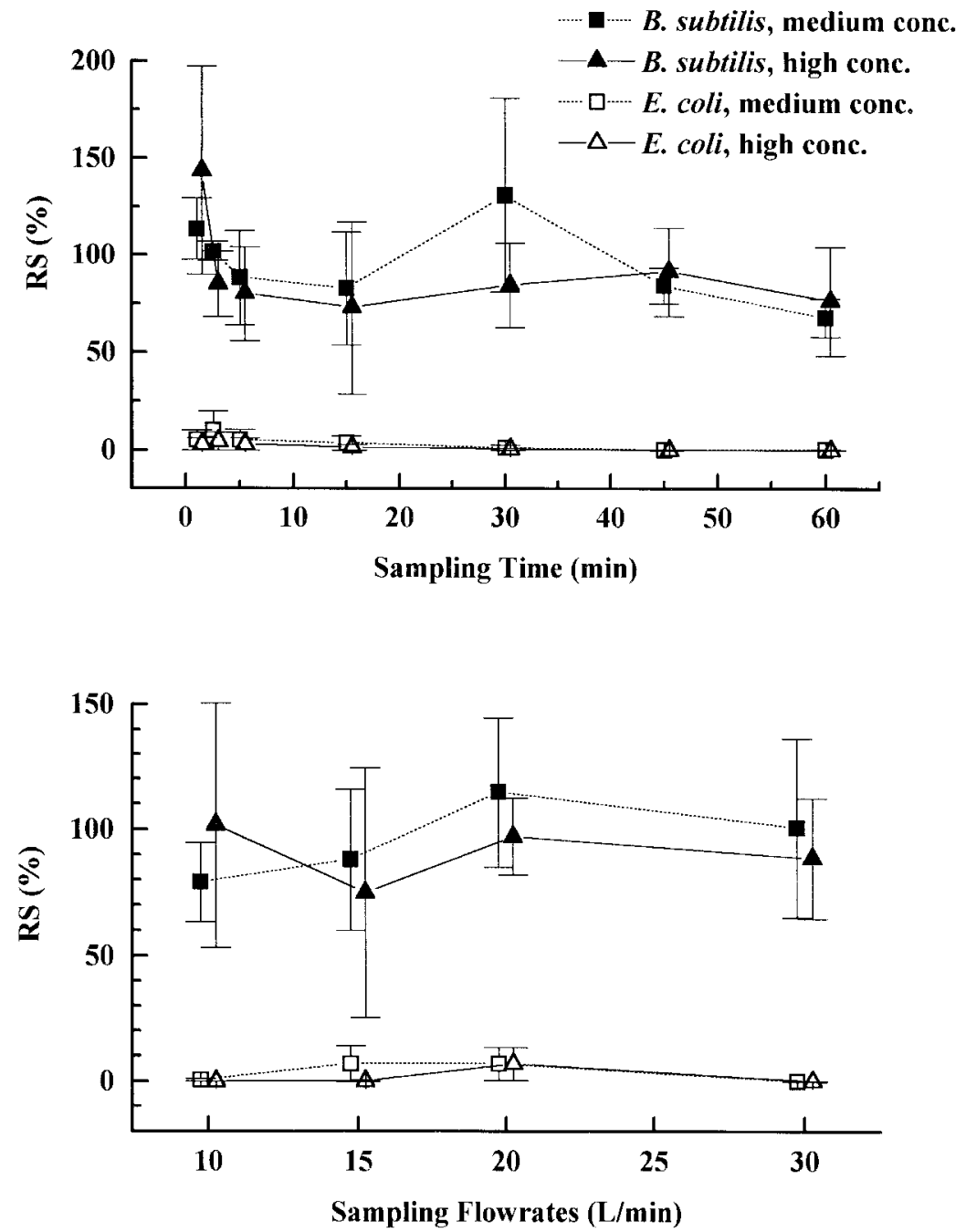

FIGURE 3. The average relative survival (RS in $\%: \mathrm{CFU} / \mathrm{m}^{3}$ concentration divided by $\mathrm{CFU} / \mathrm{m}^{3}$ concentration measured simultaneously by an AGI-30 at a flow rate of $12.5 \mathrm{~L} / \mathrm{min}$ ) of gelatin filters for $E$. coli and $\mathrm{B}$. subtilis at different sampling times and flow rates. In the upper figure, each error bar represents one standard deviation on the mean of four different sampling flow rates. In the lower figure, each error bar represents one standard deviation on the mean of seven different sampling times.

likely to perform better than filtration methods for sampling airborne bacterial microorganisms.

This work was supported by grant IOSH85-H301 from the Institute of Occupational Safety and Health, Council of Labor, Republic of China.

\section{References}

Brachman, P. S., Ehrich, R., Eichenwald, H. F., Gabelli, V. J., Kethley, T. W., Madin, S. H., Maltman, J. R., Middlebrook, G., Morton, J. D., Silver, I. H., and Wolfe, E. K. (1964). Standard Sampler for Assay of Airborne Microorganisms, Science 144:1295.

Crook, B. (1995) Non-Inertial Samplers: Biological Perspectives. In Bioaerosols Handbook, edited by 
C. S. Cox and C. M. Wathes. CRC Lewis Publishers, Boca Raton, FL, pp. 269-283.

Griffiths, W. D., and DeCosemo, G. A. L. (1994). The Assessment of Bioaerosols: A Critical Review, $J$. Aerosol Sci. 25:1425-1458.

Grinshpun, S. A., Willeke, K., Ulevicius, V., Juozaitis, A., Terzieva, S., Donnelly, J., Stelma, G. N., and Brenner, K. P. (1997). Effect of Impaction, Bounce, and Reaerosolization on the Collection Efficiency of Impingers, Aerosol Sci. Technol. 26:326-342.

Henningson, E. W., and Ahlberg, M. S. (1994). Evaluation of Microbiological Aerosol Samplers: A Review, J. Aerosol Sci. 25:1459-1492.

Jensen, P. J., Todd, W. F., David, G. N., Scarpino, P. V. (1992). Evaluation of Eight Bioaerosol Samplers Challenged with Aerosols of Free Bacteria, Am. Ind. Hyg. Assoc. J. 53:660-667.

Lembke, L. L., Kniseley, R. N., Van Mostrand, R. C., and Hale, M. D. (1981). Precision of the All-Glass Impinger and the Andersen Microbial Impactor for Air Sampling in Solid-Waste Handling Facilities, Appl. Environ. Microbiol. 42:222-225.

Lin, X., Willeke, K., Ulevicius, V., and Grinshpun, S. A. (1997). Effect of Sampling Time on the Collection Efficiency of All-Glass Impingers, Am. Ind. Hyg. Assoc. J. 58:480-488.

Macher, J. M., and First, M. W. (1984). Personal Air Samplers for Measuring Occupational Exposures to Biological Hazards, Am. Ind. Hyg. Assoc. J. 45:76-83.

Macher, J. M., and Willeke, K. (1992). Performance Criteria for Bioaerosol Samplers, J. Aerosol Sci. 23:S647-S650.
May, K. R., and Harper, G. J. (1957). The Efficiency of Various Liquid Impinger Samplers in Bacterial Aerosols, Brit. J. Ind. Med. 14:287-297.

Nevalainen, A., Pastuszka, J., Liebhaber, F., and Willeke, K. (1992). Performance of Bioaerosol Samplers: Collection Characteristics and Sampler Design Considerations, Atmos. Environ. 26A:531-540.

Nevalainen, A., Willeke, K., Liebhaber, F., Pastuszka, J., Burge, H., and Henningson, E. (1993). Bioaerosol Sampling. In Aerosol Measurement: Principles, Techniques, and Applications, edited by K. Willeke and P. A. Baron. Van Nostrand Reinhold, New York, pp. 471-492.

Rotter, M., and Koller, W. (1973). Sampling of Airborne Bacteria by Gelatin-foam-filters, Zbl. Bakt. Hyg., I. Abt. Orig. B. 157:257-270.

Terzieva, S., Donnelly, J., Ullevicius, V., Grinshpun, S. A., Willeke, K., Stelma, G. N., and Brenner, K. P. (1996). Comparison of Methods for Detection and Enumeration of Airborne Microorganisms Collected by Liquid Impingement, Appl. Environ. Microbiol. 62:2264-2272.

Thompson, M. W., Donnelly, J., Grinshpun, S. A., Juozaitis, A., and Willeke, K. (1994). Method and Test System for Evalaution of Bioaerosol Sampler, J. Aerosol Sci. 25:1579-1594.

Thorne, P. S., Kiekhaefer, M. S., Whitten, P., and Donham, K. J. (1992). Comparison of Bioaerosol Sampling Methods in Barns Housing Swine, Appl. Environ. Microbiol. 58:2543-2551.

Received November 17, 1997; accepted September 14, 1998. 